\title{
Control and Design Constraints of Compensators for Mitigation of Harmonics in Photovoltaic Inverter
}

\author{
Kalaiarasi N, Anitha D, Uthra R
}

\begin{abstract}
Compensators are devices which diminish the current harmonics of the lower order which are injected to the electric grid to meet the international standards. Resonant compensators are used to reduce the particular harmonics in grid-connected photovoltaic inverters. This paper presents how the harmonics are mitigated within the standards by using lead, lag, lead-lag compensators. The frequency deviation and transient response are considered the important factors during the design of the compensators. MATLAB design of grid connected photovoltaic inverter is presented with simulation result. A hardware of three phase photovoltaic load connected inverter with LCL filter was implemented. The simulation and experimental results of Grid connected Photovoltaic inverter with and without compensation are discussed. The harmonic profiles of these compensators are also presented.
\end{abstract}

Keywords: Quasi-ZSI, PV array, lead, lag, lead-lag compensator, LCL filter, MPPT, THD.

\section{INTRODUCTION}

The solar photovoltaic system consists of PV arrays, QZSI, controller and compensators to form a distributed generation. The design of the photovoltaic system is flexible to accomplish the functions such as maximum power point tracking, conversion and grid synchronization. The integration of PV inverter to the grid is achieved based on the international standards related to power quality, equipment protection, safety, etc. the quality of output power from the inverter is constrained by voltage limits, frequency and harmonics. Variations from these limits are represented as abnormal conditions. If the inverter operates in non-islanding mode during abnormal condition it should disconnect from the electrical grid [1-2].

The injection of lower order current harmonics is possible using selective harmonic compensation. In the literature, numerous algorithms are used based on the control theory provide excellent results in the expense of complex design and implementation. For PV applications selective harmonic compensation with linear control scheme is developed. It comprises of group of integrators which is also called as BPF
(Band Pass Filters) that are tuned to resonate at particular frequency. Each integrator mitigates a specific grid current harmonic. An ideal integrator ensures a near perfect harmonic elimination theoretically with an infinite gain at resonant frequency. Unfortunately, ideal integrators cannot be realized in digital system. hence, a comprehensive damped integrator is proposed in which it has limited gain at resonant frequency. Design of these harmonic compensators requires a systematic procedure which arbitrates grid synchronization, transient response, frequency deviation and harmonic injection.

This paper, presents a design of inverter and compensators for grid-connected PV applications. The inverter's performance is analysed based on the effect of the compensator characteristics. Here, the THD of the Quasi z-source inverter output voltage with lead, lag, lead-lag compensators are discussed.

Selective harmonic compensation is achieved with the help of resonant harmonic compensators. The higher order harmonics are eliminated with the aid of LCL filters. Thus, by improving THD of a PV system. [9]-[11].

\section{SYSTEM DESCRIPTION}

The system shown in Figure 1 consists of a PV panel which provides an input to Quasi Z-Source inverter (QZSI). Further QZSI has been associated with LCL filter and then which is connected to a grid as load. The voltage and current of the grid side is sensed and are given to phased locked loop (PLL). PLL is intended for the purpose of synchronizing the grid voltage with the inverter voltage. This creates the closed loop operation and reduces the injection of harmonic currents to the grid and improve the THD performance. 


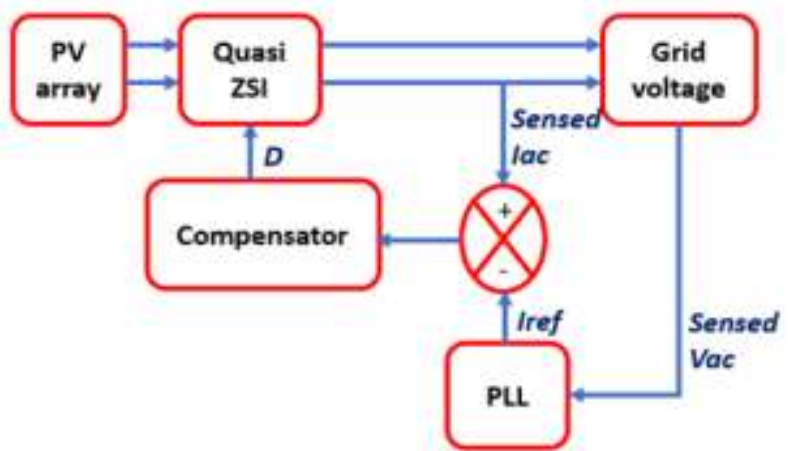

Figure 1. Block diagram of the proposed PV integrated grid connected system

\subsection{Quasi z-source inverter}

QZSI is a one stage power converter which is attained from the traditional ZSI topology, retaining an exclusive Z-source network. The traditional VSI and CSI suffers from the limitation that activating two switches in the same leg or phase that leads to a short circuit with the source and in addition, the extreme output voltage cannot exceed the input DC voltage. These shortcomings can be overcome by both ZSI and QZSI, by employing some shoot-through zero states. A zero state is formed either the upper three switches or lower three switches are gated on instantaneously to boost the output voltage. Based on the voltage boost requirements, the zero states of the VSI can be replaced completely or partially by the shoot through state along with six active states.

QZSI attain all the advantages of traditional ZSI. Along with that, this topology draws a fixed current from the PV panel and in a position to handle a wide ranges of input voltage. Also, QZSI has lower device ratings, reduces switching ripples and source stress compared with traditional ZSI. The inductor, capacitor and diode associated to the inverter bridge alter the working of the circuit, permitting the shoot-through state which is prohibited in traditional VSI. With the help of shoot-though state in Quasi Z-source network, the dc-link voltage is improved [12]-[16].

\subsection{Harmonic compensator}

The system oscillates with greater magnitude at some frequencies than other frequencies is called as resonance. At resonant frequencies, a small episodic driving forces can produce larger magnitude oscillations, due to the fact that the system stores vibration energy. During energy transfer between two or more storage modes, there are some losses occur from cycle to cycle, called damping. When the damping factor is less, the resonant frequency is approximately same as that of the natural frequency of the system. Some systems have multiple, distinct, resonant frequencies.

$$
\begin{aligned}
& G_{c}(s)=\frac{P}{Z}\left(\frac{s+Z}{s+P}\right) \\
& \text { if }(P>Z) \ldots \text {... lead }(P<Z) \ldots \text {... lag }
\end{aligned}
$$

If $(P>Z)$ in equation (1) denotes the lead compensator, otherwise lag compensator. Lead compensator is a PD type compensator and increases the system bandwidth which is relates to decrease in rise, settling times and a weakness to high frequency noise. The phase margin and relative stability is increased due to the increase in phase of the forward-path near the zero-gain crossover frequency.

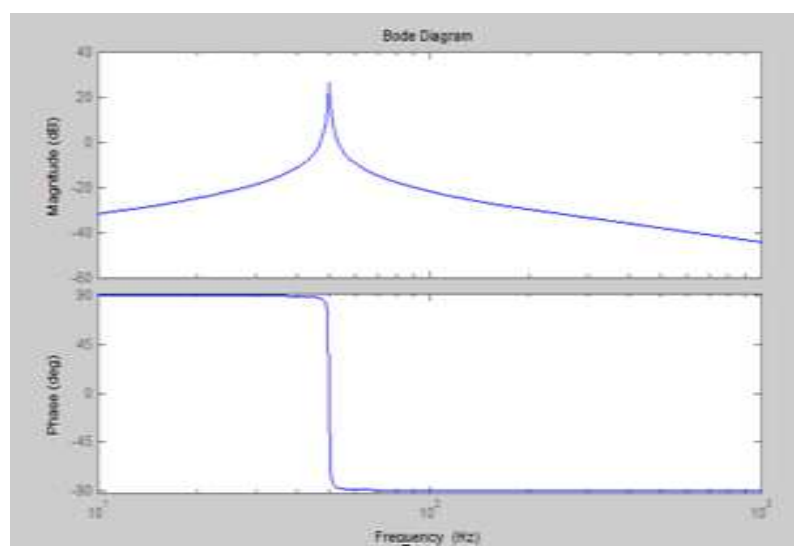

Figure 2 Magnitude and phase plot of the lead compensator

Figure 2 represents the magnitude and phase plot of the lead compensator. It is observed that, resonance occurred at $50 \mathrm{~Hz}$ and the magnitude goes very high which is equal to 30 db. In Equation (1), $(\mathrm{P}<\mathrm{Z})$ represents the phase lag compensator, also referred as PI type compensation. Lag compensator reduces the bandwidth which is relates to increase in rise, settling times. Also, less susceptibility for high frequency noise, which attenuates the forward path gain near and above the zero-gain crossover frequency. This improves the relative stability of the system and reduces steady-state error [17-20].

$$
\begin{aligned}
& G_{c}(s)=\frac{P_{1} P_{2}}{Z_{1} Z_{2}}\left(\frac{S+Z_{1}}{S+P_{1}}\right)\left(\frac{S+Z_{2}}{S+P_{2}}\right) \\
& \text { if }\left(P_{1}>Z_{1}\right) \text { and }\left(P_{2}<Z_{2}\right)
\end{aligned}
$$

Bandwidth of the system is increased and also faster response is achieved at lower frequencies using lead compensator. The lag compensator is used for reducing steady state error and susceptibility to high frequency noise. Equation (2) refers the lead-lag compensator. The requirements for the grid connected PV inverters are total harmonic grid current distortion is less than $5 \%$, frequency deviation $1 \mathrm{~Hz}$ and power factor angle are less than 2.6 degrees.

\subsection{LCL Filter}

The LCL filter provides good current ripple attenuation even with less inductance values. The filter must be designed based on the inverter parameters. One of the important parameters is cut-off frequency, which has the value of at least one half of the switching frequency of the inverter. hence, the filter has adequate attenuation in the range switching frequency of the inverter. The cut-off frequency of the LCL filter can be calculated using equation (3) 


$$
f_{r e z}=\frac{1}{2 \pi} \sqrt{\frac{L_{1}+L_{2}}{L_{1} L_{2} C}}
$$

Also,

$$
10 f_{g}<f_{r}<\frac{f_{m}}{z}
$$

In equation (4), fg \& fsw denotes the grid and switching frequency respectively. The damping resistor $\mathrm{Rd}$ is calculated using equation (5)

$$
R d=13 C \omega r
$$

Synchronization of renewable source with grid is an inspiring task exclusively when the signals from the utility is contaminated with harmonics. A phase detecting technique PLL is used for grid synchronization.

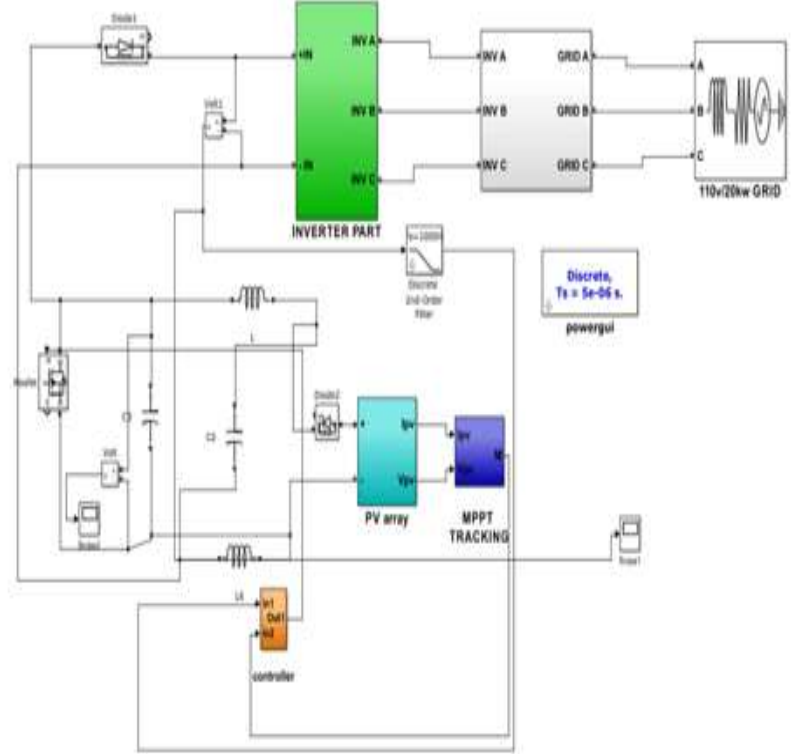

Figure 3 Simulink model of the grid integrated PV system with compensator

The specifications of the grid connected photovoltaic inverter system is shown in Table 1.

Table 1. Parameter Specifications of grid connected PV inverter system

\begin{tabular}{|l|l|}
\hline Parameters & Value \\
\hline Grid voltage, Vg & $230 \mathrm{~V}$ \\
\hline Grid frequency, fg & $50 \mathrm{~Hz}$ \\
\hline Switching frequency, fs & $18 \mathrm{kHz}$ \\
\hline Cut-off frequency, fres & $1300 \mathrm{~Hz}$ \\
\hline $\begin{array}{l}\text { Inductance present in } \\
\text { inverter side, L1 }\end{array}$ & $2.14 \mathrm{mH}$ \\
\hline $\begin{array}{l}\text { Inductance present in } \\
\text { gid side, L2 }\end{array}$ & $1.32 \mathrm{mH}$ \\
\hline Filter capacitor, C & $1 \mu \mathrm{F}$ \\
\hline Damping resistance & $0.19 \mathrm{ohms}$ \\
\hline $\begin{array}{l}\text { Grid frequency } \\
\text { deviation }\end{array}$ & $\pm 1 \mathrm{~Hz}$ \\
\hline Power factor angle & $\begin{array}{l}\text { Less than 2.6 } \\
\text { degree }\end{array}$ \\
\hline
\end{tabular}

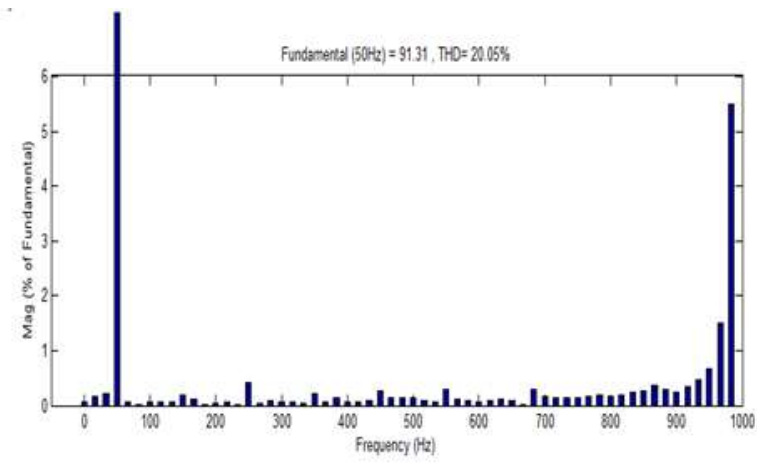

Figure 4 Harmonic profile without compensator

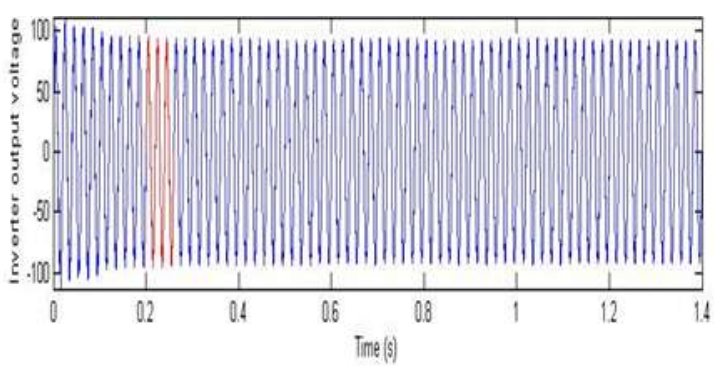

Figure 5 Inverter output voltage with lag compensator

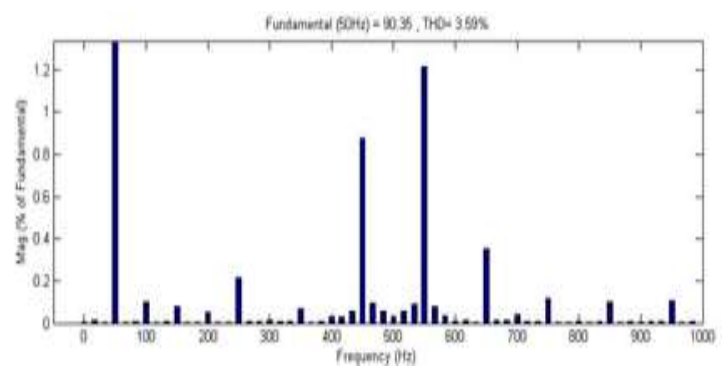

Figure 6 Harmonic profile with lag compensator

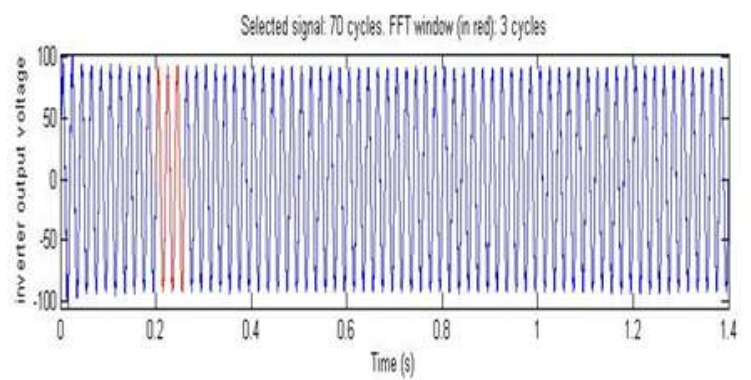

Figure 7 Inverter output voltage with lead compensator 


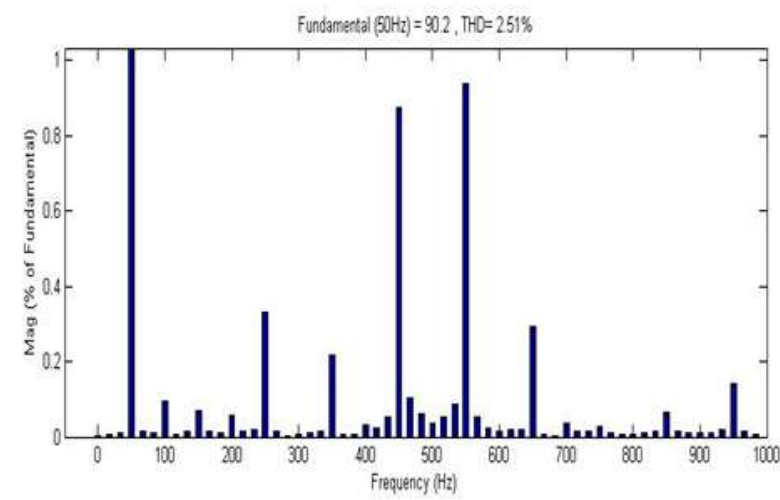

Figure 8 Harmonic profile with lead compensator

It is observed from the harmonic profiles shown in Figure 4 to Figure 8, the total harmonic distortion after using lag, lead compensators are reduced from $20.05 \%$ to $3.59 \%$, $2.51 \%$ respectively for a QZSI output voltage. From the above results, lead compensator further improves the harmonic profile. Table 2 shows the evaluation of the harmonic profile for various compensators.

\begin{tabular}{|l|l|l|l|}
\hline $\begin{array}{l}\text { Compensator } \\
\text { type }\end{array}$ & Lag & Lead & $\begin{array}{l}\text { Lead- } \\
\text { lag }\end{array}$ \\
\hline $\begin{array}{l}\text { Inverter } \\
\text { output voltage }\end{array}$ & 90.42 & 90.18 & 90.24 \\
\hline $\begin{array}{l}\text { THD for } \\
\text { inverter } \\
\text { output voltage }\end{array}$ & $3.59 \%$ & $2.51 \%$ & $2.56 \%$ \\
\hline
\end{tabular}

Table 2. Harmonic profile for compensators

\section{HARDWARE IMPLEMENTATION \& RESULTS}

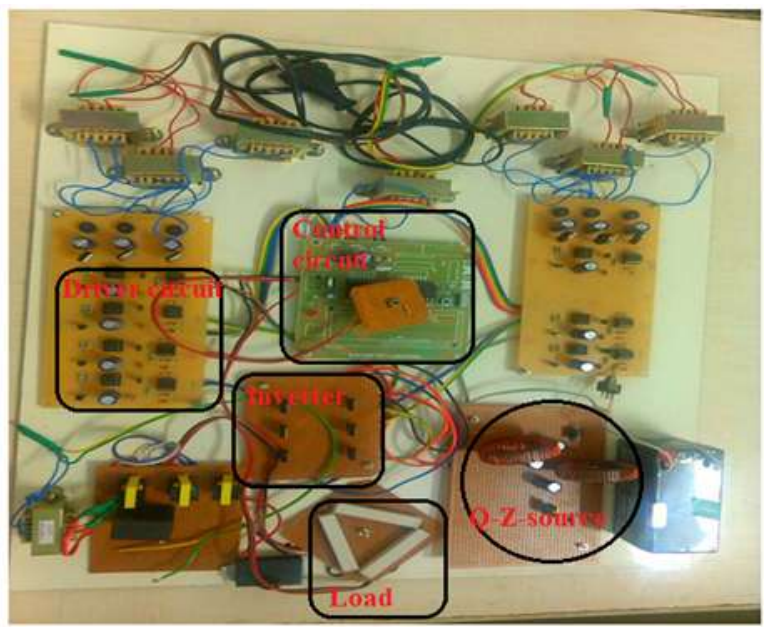

Figure 9 Experimental set up for proposed system QZSI is used to convert DC to AC and boost the input DC voltage. DsPIC30F4011 controller is used in this project for implementing the lead compensator and obtaining the PWM pulses for MOSFET switch which is available in QZSI. The MOSFET's, are used in this hardware setup is FGA25N120ANTD have a rating of $1000 \mathrm{~V}$ and 1A under standard operating conditions.

The isolation circuit provides separation between the power circuit and the controller. It is required because the board is sensitive and operates at very low voltage levels. The opto-couplers are also used to prevent the reverse current flowing from inverter circuit to the controller.

The power supply circuit consist of few stages. First the AC supply $230 \mathrm{~V}$ is reduced to $12 \mathrm{~V}$ with the help of step-down transformer and then it is converted to DC using Diode bridge rectifiers (DBR). The DBR output is given to filter circuit and followed by voltage regulator IC.

The PWM generated from the controller is $5 \mathrm{~V}$, which is not enough to drive the MOSFET switches. Due to this the voltage level of the pulses areraised to $15 \mathrm{~V}$ with the help of driver circuit then given to gate terminal of the MOSFET switches. The obtained PWM from driver circuit is shown in Figure 14. The PV integrated with QZSI transfers the extreme power from the PV to the grid by MPPT algorithm. In this work perturb and observe MPPT is used. QZSI when implement with the improved control techniques such as maximum boost and modified boost control method can provide better interface to PV system and also can provide greater efficiency.

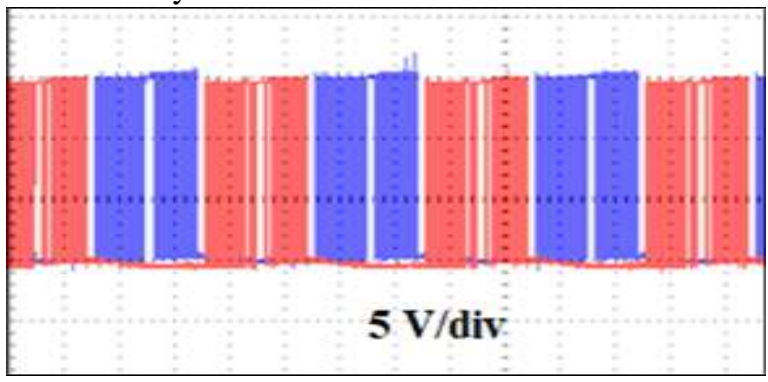

Figure 10 Pulses for inverter switches

Figure 10 represent the PWM pulses for switches in one phase. The pulse shown in channel 1 is for T1 and channel 2 for T2 shown in red and blue color respectively in scope.

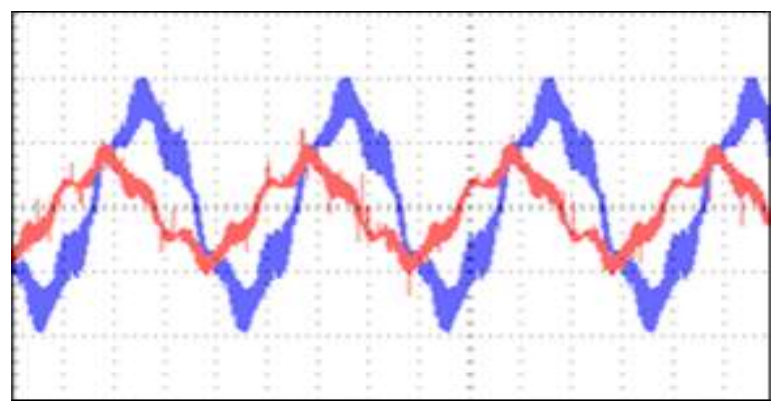

Figure 11 Output waveform across load without compensation

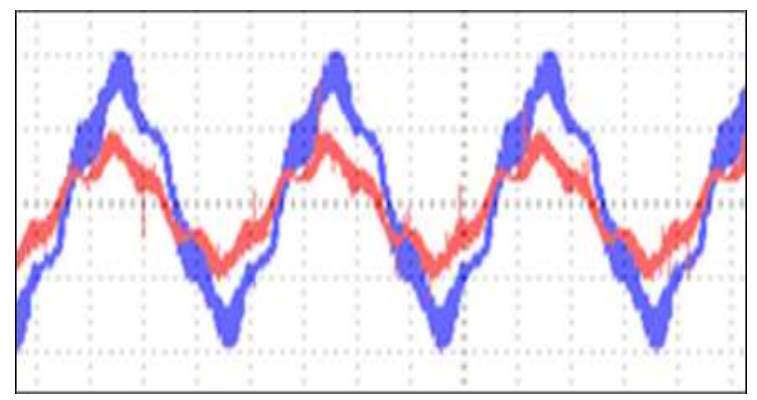

Figure 12 Output waveform across load with compensation 
The DSO output waveform shown in Figure 11 and Figure 12 represents the voltage and current waveforms across the delta connected $\mathrm{R}$ load for one phase without compensation and with compensation respectively.it is observed from the outputs the compensator also decreases the phase angle between voltage and current.

\section{CONCLUSION}

In this paper, lead, lag, lead-lag compensators are used to obtain the required transient response and stability that improves harmonic profile. Simulations for the grid integrated inverter with LCL filter and with lead, lag, lead-lag compensator are carried out and their output waveforms and harmonic profiles are presented in section 2 . It is observed that, improvement in the harmonic profile and proper damping is obtained by adding Lead compensator in the proposed system. Prototype model of photovoltaic inverter with lead compensator are performed and selected experimental results are also described. The controller is implemented using a DsPIC30F4011 microcontroller. The load voltages are compared with and without compensator.

\section{REFERENCE}

1. S. B. Kjaer, J. K. Pedersen, and F. Blaabjerg, "A review of single-phase grid-connected inverters for photovoltaic modules," IEEE Trans. Ind. Appl., vol. 41, no. 5, pp. 1292-1306, Sep./Oct. 2005.

2. R. Teodorescu, F. Blaabjerg, U. Borup, and M. Liserre, "A new control structure for grid-connected LCL PV inverters with zero steady-state error and selective harmonic compensation," in Proc. IEEE APEC, 2004, pp. 580-586.

3. LCL-filter Design for Grid-Connected PCS Using Total Harmonic Distortion and Ripple Attenuation Factor, The 2010 International Power Electronics Conference.

4. Design and Research on the LCL Filter in Three-Phase PV Grid-Connected Inverters, International Journal of Computer and Electrical Engineering, Vol. 5, No. 3, June 2013.

5. N. Femia, G. Lisi, G. Petrone, G. Spagnuolo, and M. Vitelli, "Distributed maximum power point tracking of photovoltaic arrays: Novel approach and system analysis," IEEE Trans. Ind. Electron., vol. 55, no. 7, pp. 2610-2621, Jul. 2008.

6. J. M. Carrasco, L. Garcia Franquelo, J. T. Bialasiewicz, E. Galván, R. C. Portillo Guisado, M. A. Martín Prats, J. I. León, and N. Moreno Alfonso, "Power-electronic systems for the grid integration of renewable sources: A survey," IEEE Trans. Ind. Electron., vol. 53, no. 4, pp. 1002-1016, Jun. 2006

7. M. Liserre, R. Teodorescu, and F. Blaabjerg, "Multiple harmonics control for three-phase grid converter systems with the use of PI-RES current controller in a rotating frame," IEEE Trans. Power Electron., vol. 21, no. 3, pp. 836-841, May 2006.

8. F. Blaabjerg, R. Teodorescu, M. Liserre, and V. Timbus, "Overview of control and grid synchronization for distributed power generation systems," IEEE Trans. Ind. Electron., vol. 53, no. 5, pp. 1398-1409, Oct. 2006.

9. X. Yuan, W. Merk, H. Stemmler, and J. Allmeling, "Stationary-frame generalized integrators for current control of active power filters with zero steady-state error for current harmonics of concern under unbalanced and distorted operating conditions," IEEE Trans. Ind. Appl., vol. 38, no. 2, pp. 523-532, Mar./Apr. 2002.

10. T. Ahmed, K. Nishida, and M. Nakaoka, "Advanced control of PWM converter with variable speed induction generator," IEEE Transaction on Industrial Applications, vol. 42, no. 4, pp. 934-945, Jul./Aug. 2006.

11. Characteristics of the Utility Interface for Photovoltaic (PV) Systems, IEC61727, Dec. 2004

12. N.Kalaiarasi, S.Paramasivam and Sanchari Kundu, "Control of Z-Source inverter based PV system with MPPT using ANFIS, "International Review on Modelling and Simuations, Vol 7,N.5 Oct 2014.

13. Baoming Ge, HaithamAbu-Rub, FangZheng Peng, Qin Lei, Student, AníbalT. de Almeida,Fernando J.T. E. Ferreira, Dongsen Sun, and YushanLiu, An Energy-Stored Quasi-Z-Source Inverter for Application to Photovoltaic Power System, IEEE Transactions On Industrial Electronics,vol.60,n.10,Oct 2013

14. YuanLi,ShuaiJiang, JorgeG. Cintron-Rivera,and Fang Zheng Peng, , Modeling and Control of Quasi-Z-SourceInverter for Distributed Generation Applications, IEEE Transactions On Industrial Electronics, vol. 60,n. 4, April, 2013

15. Sengodan Thangaprakash,Ammasai Krishnan "A new Switching Scheme for Z-source inverter to Minimize ripples in the Z-source Elements" april 2012, 200-210.

16. R. Seyezhai, Abinaya K, Akshaya V and Induja U" Simulation, Analysis and Development of Pv Fed Quasi Impedance Source Inverter" International Journal of Electrical and Electronics, vol. 3, Aug 2013, pp. 201-212.Signature Analysis as a Medium for Faults Detection", IEEE Transactions on Industrial Electronics, Vol. 47, No. 5, October 2000.

17. Chang ChiehHang, Qing-GuoWang, ZhenYe, "Tuning of Lead Compensators with Gain and Phase Margin specifications", IFAC proceedings, Vol. 38, issue 1, 2005.

18. D. Penchalaiah, Murali Mohan Gade, G. Naresh Kumar, S. E. Talole, "Optimal Compensator Design using Genetic Algorithm”, IFAC proceedings, Vol. 38, issue 1, pp 518-523, 2018.

19. A. P. Loh, X. Cai, W. W. Tan, "Auto-tuning of phase lead/lag compensators", Automatica, vol 40, issue 3, pp. 423-429, 2004.

20. De-Jin Wang, "Synthesis of phase-lead/lag compensators with complete information on gain and phase margins", Automatica, Vol.45, Issue 4, Pp.1026-1031, 2009. 